American Journal of Biotechnology and Biochemistry 3 (3): 159-162, 2007

ISSN 1553-3468

(C) 2007 Science Publications

\title{
Identification of Novel Chromosomal Abnormalities, inv(5)(p13q13) and t(7;18)(q32;q21), Associated with Autism
}

\author{
${ }^{1}$ Zheng Chen, ${ }^{2}$ Xiao-bing Zou, ${ }^{1}$ Ya-nan Zhang, ${ }^{1}$ Xin-ming Son, ${ }^{1}$ Chun-non Huang and ${ }^{3}$ Damu Tang \\ ${ }^{1}$ Department of Medical Genetics, Zhongshan Medical College \\ ${ }^{2}$ Department of Paidonosology, The $3^{\text {rd }}$ Affiliated Hospital, \\ Sun Yat-sen University, Guangzhou, PR China \\ ${ }^{3}$ Division of Nephrology, Department of Medicine, McMaster University, Hamilton, Ontario, Canada
}

\begin{abstract}
Autism is a neurodevelopmental disorder defined by impairments in social interaction, communication, as well as restricted and stereotyped behaviors. While the etiology of autism remains largely unknown, the existence of genetic components has been clearly demonstrated in autistic pathogenesis. The incidence of autism is $50-100$ fold greater in the population with autistic family history than the general population. Chromosomal abnormalities in 15q11-13 and 7q22-32 regions have been frequently detected in autistic patients. Abnormalities in other chromosomal regions, including $14 \mathrm{q} 32.3$ deletion and $\mathrm{t}(5 ; 18)(\mathrm{q} 33.1 ; \mathrm{q} 12.1)$ translocation, have also been reported. Despite these progresses, the exact genetic changes which underlie the disorder remain elusive. We report here two novel chromosomal abnormalities, an inversion $\operatorname{inv}(5)(\mathrm{p} 13 ; \mathrm{q} 13)$ and a translocation $\mathrm{t}(7 ; 18)(\mathrm{q} 32 ; \mathrm{q} 21)$ in two autistic children. These findings may help to identify the candidate genes, whose aberrations may contribute to autistic pathogenesis.
\end{abstract}

Key words: autism, reciprocal translocation $\mathrm{t}(7 ; 18)(\mathrm{q} 32 ; \mathrm{q} 21)$, inversion inv(5)(p13q13)

\section{INTRODUCTION}

Autism is a neurodevelopmental disease characterized by deficits in social interaction, communication, and restricted and stereotyped behaviors. The incidence was previously estimated to be 2-5/10,000 and has recently increased to 1 in 1000, owing to our improved understanding of the disease $\mathrm{e}^{[1]}$. Autism usually starts in early childhood with apparent clinical presentation by 3 years of age $\mathrm{e}^{[2]}$. The disease affects more boys than girls at the ratio of $4: 1^{[3]}$. While the etiology of autism remains largely unknown, family-based studies clearly demonstrate the existence of genetic components in autistic pathogenesis. The incidence of autism is 50-100 fold greater in the population with autistic family history than the general population ${ }^{[4]}$. The concordance rate for monozygotic twins is $92 \%$ compared to $10 \%$ concordance for dizygotic twins based on a broader spectrum of autism ${ }^{[5-7]}$. Consistent with these population studies, chromosomal abnormalities in 15q11-13 and 7q22-32 regions have been frequently detected in autistic patients $^{[1,2]}$. Duplication or triplication of 15q11-13 occurs in approximately $1 \%$ of autistic patients via maternal transmission ${ }^{[8-10]}$. However, the affected genes due to these abnormalities, which contribute to autism, have not been convincingly identified ${ }^{[1]}$. While several attractive candidate genes have been found in 7q22-32, including the FOXP2 gene in the SPCH1 locus and the $R E L N$ gene, some later investigations failed to correlate these genes with autistic individuals ${ }^{[2]}$. Abnormalities in other chromosomal regions, including $7 \mathrm{q} 35-36^{[11,12]}$, $14 \mathrm{q} 32.3$ deletion $^{[13]}$ and $\mathrm{t}(5 ; 18)(\mathrm{q} 33.1 ; \mathrm{q} 12.1)$ translocation $^{[14]}$, have also been reported.

We report here two novel chromosomal abnormalities observed in two autistic children, $\operatorname{inv}(5)(\mathrm{p} 13 ; \mathrm{q} 13)$ and $\mathrm{t}(7 ; 18)(\mathrm{q} 32 ; \mathrm{q} 21)$, while their parents and sister showed normal karyotypes. This indicates the involvement of novel genes during the development of autistic pathogenesis.

\section{MATERIALS AND METHODS}

Patients: Two autistic children were diagnosed at the $3^{\text {rd }}$ Affiliated Hospital, Sun Yat-sen University, Guangzhou, PR China by two physicians according to the DSM-IV diagnostic criteria and diagnostic algorithm. We have followed the patients up to now for 7 and 10 years, respectively, and are still observing them.

Corresponding Author: $\quad$ Dr. Zhen Chen, Department of Genetics, Sun Yat-sen University, Guangzhou, PR China; Dr. Damu Tang, Department of Medicine, McMaster University, Hamilton, ON, Canada 
Cytogenetic analysis: Peripheral blood samples were collected from autistic children, their parents, and sister with patients' permission and according to Hospital's regulation. Whole blood was incubated at $37^{\circ} \mathrm{C}$ in RPMI1640, calf serum, and PHA (Phytohemagglutinin) (RPMI1640:calf serum:PHA at 200:60:10) for 70 hours. Colchicine at $0.02 \mu \mathrm{g} / \mathrm{ml}$ was then added. The mixture was incubated at $37^{\circ} \mathrm{C}$ for $2-4$ hours and centrifuged at $1,500 \mathrm{rmp}$ for 8 minutes. Cell pellet was dissolved immediately in a pre-warmed $\left(37^{\circ} \mathrm{C}\right) 0.075 \mathrm{M}$ $\mathrm{KCl}(8 \mathrm{ml})$ solution, followed by incubation in a $37^{\circ} \mathrm{C}$ water-bath for 30 minutes, addition of ice-cold methanol:acetic acid (3:1) solution $(1 \mathrm{ml})$, and centrifugation at $1,500 \mathrm{rpm}$ for 8 minutes. Cell pellet was washed twice by dissolving in an $8 \mathrm{ml}$ fix solution (methanol:acetic acid 3:1) and centrifugation at $1,500 \mathrm{rpm}$ for 8 minutes, which was subsequently resuspended in the fix solution $(8 \mathrm{ml})$ and incubated at $4^{0} \mathrm{C}$ for 12 hours. This was followed by a centrifugation at 1,500rpm for 8 minutes, dissolving cells in the fix solution $(300 \mu \mathrm{l})$ at $4^{0} \mathrm{C}$, transferring $100 \mu \mathrm{l}$ of the cell solution to an ice-cold slide, and incubating slides in an oven at $75^{\circ} \mathrm{C}$ for 2-3 hours. G-band processing was then carried out by treating slides with $0.0025 \%$ trypsin (0.0025 gram of trypsin dissolved in $100 \mathrm{ml}$ of $0.9 \%$ sodium chloride) for 80 seconds and staining chromosomes with a 5\% Giemsa solution for 8 minutes at $37^{\circ} \mathrm{C}$. G-bands at the $350-550$ level were examined using a light microscope.

\section{RESULTS}

Identification of inv(5)(p13q13) in an autistic girl: Patient \#1 is a female born at the $39^{\text {th }}$ week of gestation following an uncomplicated pregnancy and weighed $2,750 \mathrm{~g}$ at birth. She started to walk at 14 months of age. Her IQ was 48 and 54 at the ages of 25 months and 7 years, respectively. The child displayed impairments in social interaction at 2 years of age and was diagnosed with atypical autism at the age of 6 years. Behaviorally, she was shy, played by herself, showed no reciprocity with others, and did not display initiatives to share with others her enjoyment, interests, or achievements. While her vision and hearing were normal, there was no speech and language development at 4 years. Magnetic resonance imaging of her brain did not show any structural anomalies. There was no family history of neurodevelopmental abnormalities. She has a younger sister who was healthy at 2 years of age.

As approximately $5-10 \%$ of autistic patients are associated with chromosomal abnormalities that can be used as a supportive criterion for autism diagnosis ${ }^{[15]}$, we have performed routine cytogenetics at the 350-550 G-band level using standard protocols. Peripheral blood samples were collected from this patient, her parents, and her younger sister. While her parents and younger sister had normal karyotypes, the patients karyotype was 46, XX, inv(5)(p13q13) (Fig 1), suggesting that this inversion may contribute to the patient's autistic pathology.

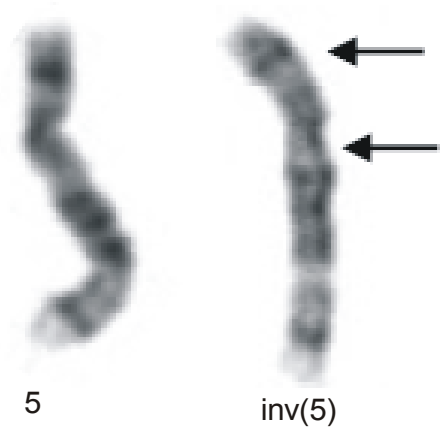

Fig. 1: G-band analysis of chromosome abnormalities detected in an autistic girl. This patient contains inv5(p13q13). Arrows indicate the breakpoints.
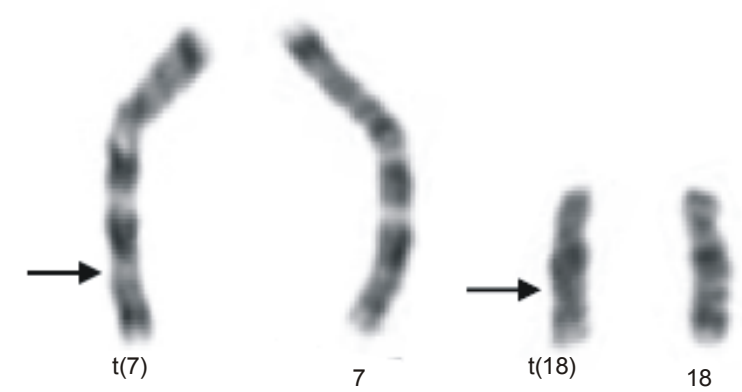

Fig. 2: G-band analysis of chromosome abnormality in an autistic boy. This patient has a translocation between chromosomes 7 and 18 , $\mathrm{t}(7,18)(\mathrm{q} 32 ; \mathrm{q} 21)$. Arrows show the breakpoints.

Identification of $t(7 ; 8)(q 32 ; q 21)$ in an autistic boy: Patient \#2 is 10-year-old boy born after a normal pregnancy weighing $4,100 \mathrm{~g}$. He was able to sit at the age of 10 months and to crawl at 1 year old. The child started to walk at 2 years of age. At age 4, his vocabulary was limited to the words "Mom" and "Dad", and could not speak in complete sentences at the age of 7 years. He was unable to express his needs and either spoke words that were unrelated to his surroundings or made incoherent strange sounds. The 
child was unable to focus on things and showed reduced understanding. He played by himself and did not communicate with others. His vision and hearing abilities are normal. There was no family history of abnormal neurodevelopmental conditions. After excluding other pathological factors including fragile $\mathrm{X}$ syndrome, tuberous sclerosis, and environmental effects during pregnancy, the child was diagnosed with autism according to the DSM-IV diagnostic criteria and diagnostic algorithm by two physicians.

To determine whether Patient \#2 is associated with chromosomal abnormalities, cytogenetic analysis was performed on the patient and his parents. G-band results showed that both the parents had normal karyotypes. Patient \#2 showed a man karyotype with an apparently balanced chromosome translocation, 46,XY,t(7;8)(q32;q21) (Fig 2).

\section{DISCUSSION}

While the existence of genetic components in autistic pathogenesis is becoming increasingly convincing, the candidate genes whose aberrations contribute to autism have not been clearly identified. Efforts in the identification of these genetic components have led to the findings of several affected chromosomal regions in autistic patients, including $7 \mathrm{q} 21-7 \mathrm{q} 32^{[16]}$. Within this region, the FOXP2 gene in the SPCH1 locus, which controls language development, was initially thought to contribute to the language defects that are associated with autistic patients ${ }^{[17]}$. However, aberrations in this gene were not detected in autistic patients ${ }^{[2]}$. Other candidate genes have also been indicated in autistic pathogenesis, including the RELN at 7q22, the 5HTT (a serotonin transporter gene) at $17 \mathrm{q} 11$, and the EN2 gene ${ }^{[2]}$. Reciprocal translocation involving $7 \mathrm{q} 32$ [t(5;7)(q14;q32)] has also been reported in an autistic patient ${ }^{[18]}$.

We have identified two chromosomal abnormalities $[\operatorname{inv}(5)(\mathrm{p} 13 \mathrm{q} 13)$ and $\mathrm{t}(7 ; 18)(\mathrm{q} 32 ; \mathrm{q} 21)]$ in two autistic patients. The breakpoints at p13 and q13 of chromosome 5 and at q32 of chromosome 7 and q21 of chromosome 18 may affect the expression of candidate genes involved in autism, which is consistent with the current concept of the involvement of multiple genes in the disorder ${ }^{[19]}$. Mapping the exact breakpoints in the aforementioned chromosomal loci will help to identify the candidate genes, whose aberrations may contribute to autistic pathogenesis.

\section{CONCLUSIONS}

Two chromosomal changes, inv(5)(p13;q13) $\mathrm{t}(7 ; 18)(\mathrm{q} 32 ; \mathrm{q} 21)$, were identified in two autistic children. These changes may affect the expression of genes that reside at or near the chromosomal breakpoints. These genes are the candidate genes whose aberrations may play a role in autistic pathogenesis.

\section{ACKNOWLEDGEMENTS}

This research was funded by National Natural Science Foundation of China (Grant Number: 30640028) to Z.C. D.T was supported by Canadian Institutes of Health Research (CIHR).

\section{REFERENCES}

1. Folstein, S.E. and Rosen-Sheidley, B. 2001. Genetics of autism: complex aetiology for a heterogeneous disorder. Nat Rev Genet., 2: 943-55.

2. Bartlett, C.W., Gharani, N., Millonig, J.H. and Brzustowicz, L.M. 2005. Three autism candidate genes: a synthesis of human genetic analysis with other disciplines. Int J Dev Neurosci., 23: 221-34.

3. Fombonne, E. 1999. The epidemiology of autism: a review. Psychol Med., 29: 769-86.

4. Rutter, M. 1968. Concepts of autism: a review of research. J Child Psychol Psychiatry, 9: 1-25.

5. Folstein, S, and Rutter, M. 1977. Infantile autism: a genetic study of 21 twin pairs. J Child Psychol Psychiatry, 18: 297-321.

6. Steffenburg, S., Gillberg, C., Hellgren, L., Andersson, L., Gillberg, I.C., Jakobsson G. and Bohman M. 1989. A twin study of autism in Denmark, Finland, Iceland, Norway and Sweden. J Child Psychol Psychiatry, 30: 405-16.

7. Bailey, A., Le Couteur, A., Gottesman, I., Bolton, P., Simonoff, E., Yuzda, E. and Rutter, M. 1995. Autism as a strongly genetic disorder: evidence from a British twin study. Psychol Med. 25:63-77.

8. Cook, E.H. Jr, Lindgren, V., Leventhal, B.L., Courchesne, R., Lincoln, A., Shulman, C., Lord, C. and Courchesne, E. 1997. Autism or atypical autism in maternally but not paternally derived proximal 15q duplication. Am J Hum Genet., 60: 928-34. 
9. Browne, C.E., Dennis, N.R., Maher, E., Long, F.L., Nicholson, J.C., Sillibourne, J. and Barber, J.C. 1997. Inherited interstitial duplications of proximal 15q: genotype-phenotype correlations. Am J Hum Genet., 61: 1342-52.

10. Koochek, M., Harvard, C., Hildebrand, M.J., Van Allen, M., Wingert, H., Mickelson, E., Holden, J.J., Rajcan-Separovic, E. and Lewis, M.E. 2006. 15q duplication associated with autism in a multiplex family with a familial cryptic translocation $\mathrm{t}(14 ; 15)(\mathrm{q} 11.2 ; \mathrm{q} 13.3)$ detected using array-CGH. Clin Genet., 69: 124-34.

11. Liu, J., Nyholt, D.R., Magnussen, P., Parano, E., Pavone, P., Geschwind, D., Lord, C., Iversen, P., Hoh, J., Ott, J., Gilliam, T.C. and Autism Genetic Resource Exchange Consortium. 2001. A genomewide screen for autism susceptibility loci. Am J Hum Genet., 69: 327-40.

12. Alarcon, M., Cantor, R.M., Liu, J., Gilliam, T.C., Geschwind, D.H. and Autism Genetic Research Exchange Consortium. 2002. Evidence for a language quantitative trait locus on chromosome $7 \mathrm{q}$ in multiplex autism families. Am J Hum Genet., 70: 60-71.

13. Merritt, J.L. 2nd, Jalal, S.M., Barbaresi, W.J. and Babovic-Vuksanovic, D. 2005. 14q32.3 deletion syndrome with autism. Am J Med Genet A., 133: 99-100.

14. Kroisel, P.M., Windpassinger, C., Wagner, K., Petek, E., Vincent, J.B., Scherer, S.W., Spiel, G., Artner, V. and Valtiner, E. 2004. De novo translocation $\mathrm{t}(5 ; 18)(\mathrm{q} 33.1 ; \mathrm{q} 12.1)$ associated with autistic disorder. Am J Med Genet A., 129: 98-100.
15. Castermans, D., Wilquet, V., Steyaert, J., Van de Ven, W., Fryns, J.P. and Devriendt, K. 2004. Chromosomal anomalies in individuals with autism: A strategy towards the identification of genes involved in autism. Autism, 8: 141-61.

16. Shao, Y., Wolpert, C.M., Raiford, K.L., Menold, M.M., Donnelly, S.L., Ravan, S.A., Bass, M.P., McClain, C., von Wendt, L., Vance, J.M., Abramson, R.H., Wright, H.H., Ashley-Koch, A., Gilbert, J.R., DeLong, R.G., Cuccaro, M.L. and Pericak-Vance, M.A. 2002. Genomic screen and follow-up analysis for autistic disorder. Am J Med Genet., 114: 99-105.

17. Lai, C.S., Fisher, S.E., Hurst, J.A., VarghaKhadem, F. and Monaco, A.P. 2001. A forkheaddomain gene is mutated in a severe speech and language disorder. Nature, 413: 519-23.

18. Tentler, D., Brandberg, G., Betancur, C., Gillberg, C., Anneren, G., Orsmark, C., Green, E.D., Carlsson, B. and Dahl, N. 2001. A balanced reciprocal translocation $\mathrm{t}(5 ; 7)(\mathrm{q} 14 ; \mathrm{q} 32)$ associated with autistic disorder: molecular analysis of the chromosome 7 breakpoint. Am J Med Genet., 105: 729-36.

19. Happe, F., Ronald, A. and Plomin, R. 2006. Time to give up on a single explanation for autism. Nat Neurosci., 9: 1218-20. 